\title{
Reputation Risk from a Stakeholder Management Perspective
}

\author{
A. Aderibigbe ${ }^{1} \&$ E. Fragouli ${ }^{1}$ \\ ${ }^{1}$ University of Dundee, UK \\ Correspondence: E. Fragoui, School of Business, University of Dundee, UK. E-mail: e.fragouli@dundee.ac.uk
}

Received: May 4, 2020 Accepted: May 29, 2020 Online Published: July 13, 2020

\begin{abstract}
Stakeholders face many different risks that arise from any business activity. The stakeholder management approach is the process by which is organised, monitored and improved relationships with business stakeholders. It involves systematically identifying stakeholders; analysing their needs, expectations; planning and implementing various tasks to engage with them. Most definitions of stakeholder management tend to focus around the idea of how could stakeholders be managed in order to get them to do what is equired. The emphasis is placed on creating a stakeholder management plan that maps the level of interest and influence of stakeholders and list various levels of engagement for the different groups. This paper applies a case study methodology presenting the Wal-Mart case and the Malden Mills case to reflect the implications of stakeholder management in companies. The findings indicate the positive but also the negative implications which result when various stakeholders are neglected, and, conversely, the benefits when stakeholders are effectively engaged in corporate activities. It concludes that effective stakeholder management contributes to risk management and reputation management, as well as, to corporate social responsibility.
\end{abstract}

Keywords: stakeholder, management, risk, corporate social responsibility

\section{Introduction}

The management of stakeholders as well as their relationship with a given company has become a crucial matter not only for public relations practitioners, but also scholars and academics researching the topic. The stakeholder management approach to business incorporates information about the various stakeholders and how they affect and are affected by company operations. This report will ultimately aim to discuss and analyze the effectiveness of the stakeholder approach as actually fully serving as risk and reputation management policies themselves. First, however, we will provide some background on the actual theory as well as important related concepts and terms. Additionally, we will compare and contrast some of the various other risk management policies as well as providing practical examples in the form of case study analysis to link our theories with real world events. This report will also use literature review to assess the views and criticisms of this approach and to form a sort of proposal on the matter. By the conclusion of this report, the reader will have a comprehensive knowledge of the stakeholder management theory and if and how this approach is able to serve as a risk management policy.

Business in the modern era exist for the primary objective of generating profits. Under the stakeholder management approach, organizations can gain wealth through multifaceted relationships with any of their stakeholders. Successful corporate leaders have long understood the importance of hearing and reacting to concerns from their clients as well as the general public so that they can capitalize on new opportunities while simultaneously anticipating and mitigating crises before they fully develop (Post, Preston, and SauterSachs 2002). Despite this fact, sectors such as risk and crisis management are relatively new corporate functions that have become increasingly more commonplace in the years post World War II (Dionne 2013).

\section{A Theoretical Review and Applications}

\subsection{The Concept of Risk \& Reputation Risk}

The definition of risk is a topic that has stirred up arguments among risk practitioners. In 2002, there was a debate between some risk practitioners, David Hillson, David Hullett and Ron Kohl. Hillson and Hullett argued for a new and more expansive definition of risk that reflects "upside risk" while Ron Kohl on the other hand argued that the traditional definition of risk should be retained. The basis for the argument is whether the term risk should include both 'threat' and 'opportunity' or risk should refer exclusively to negative events, with opportunity being qualitatively distinct. (Hullet et al 2002). Some risk practitioners support Hillson and Hullett's argument while 
some support Kohl's argument. For example, (Jabagchourian \& Cvetko, 2002) Associated the use of risk exclusively to negative outcomes in projects, i.e. project threats and potential problems while opportunity is used to refer to positive outcomes. The authors argue that risk and opportunity are different therefore incorporating opportunity into the definition of risk will lead to confusion.(Jabagchourian \& Cvetko, 2002). However some other authors have a very different opinion, for example, some authors argues that "incorporation of opportunity in the definition of risk is a clear statement of intent, recognizing that both are equally important influences over project success and both need managing proactively". (Hillson, 2002). Traditional usage of the word "risk" reflects only the possibility of something bad, this is reflected in the dictionary definition of risk. In the dictionary, risk is defined exclusively in bad terms. The noun risk is defined as a situation involving exposure to danger (Oxford English dictionary 2013).

Without a doubt, the general use of the word 'risk' sees only the downside. However, sometimes, the traditional meaning of a word may defer from its meaning in the technical discipline for example the word 'value' or 'quality' have different technical meanings within the world of project management. This may be the case for the word 'risk'. Over the past decade, some professional bodies and risk management standard organizations have taken a different view of risk from the layman, they have expanded their definition of risk to include both 'upside' and 'downside'.(Hillson, 2003) For example, a quide to the project management body of knowledge (PMBOK), (2008) defines risk as "an uncertain event that if it occurs has a positive or negative effect on project objectives." Some other professional bodies have also taken this inclusive position, although it is not generally accepted.(Hillson, 2009).

Following the scandals of many companies that were considered reputable and long standing before their fall like the Enron; Arthur Anderson's melt down, Findus horse meat scandal, BP 'fat cat', Perrier product recall, Exxon Valdese environmental contamination, etc. shows that every company is at risk even the finest organisations. From across all sectors of industries- banking, insurance, oil and gas, construction, etc. reputation plays a central role on the success or failure of that industry. Reputation is considered as the reason why people and organisation do business with you and this is achieved through many years of investment (Davies, 2006) and perhaps one of the most important strategic resources of an organisation (Flanagan \& O'Shaughnessy, 2005:445; Hall, 1992 cited by Boyd et al, 2010), which helps to differentiate one organisation from the other (Peterson, 1993). Similarly, "an organisation's reputation reflects stakeholder impressions of the firm's disposition to behave in a certain manner" (Basdo et al, 2006: 1206 cited by Lange et al, 2011).

To define reputation risk (RR), Peterson, (2006), (United States Patent Application: Interactive Risk Management Systems and Methods with RRM), puts it in a clear perspective. He defines RR as "arising from situation, occurrence, business practice or an event that has the tendency to materially influence the perceived trust and confidence of the public or stakeholders in an institution, resulting in a measurable, negative impact on financial performance on a short or long-term basis, resulting in an impact on the going-forward value of a brand or franchise threatened in a material manner; and or resulting in a change in fundamental business practice required in order to mitigate the risk". This definition does not only embodies what is and can be the result of RR but also how this can be mitigated and managed- it requires best practices, an organisation wide approach and processes; reputation risk management (RRM). RRM, according to Larkin (2003), involves the anticipation and knowledge of responding to changes in values and behaviours on the part of a range of corporation's internal and external stakeholders' relations. Effective RRM depends upon identifying and control each process, and being operated holistically- not as a special function to be activated in an emergency but a major influence on the organisation's behaviours and standards but this also means committing money. "The key therefore is to understand that reputation is in all probability the biggest asset and if managed properly will have a spin-off benefits that, by themselves massively improve corporate performance and profitability" (Davies, 2006)

\subsubsection{What is Risk Management?}

Risk and complexity is a common feature of modern day business. Managers have to deal with a large array of different, yet interrelated types of risks including financial, technological, environmental safety, insurance-related and regulatory risks. Because risks impact heavily on profitability, efficiency and sustainability, its management is crucial to growth and development (Zwikael \& Ahn, 2011). In the past five years, there has been:

... a paradigm shift has occurred regarding the way organizations view risk management. Instead of looking at risk management from a silo-based perspective, the trend is to take a holistic view of risk management. This holistic approach toward managing an organization's risk is commonly referred to as enterprise risk management (ERM). Indeed, there is growing support for the general argument that organizations will improve their performance by employing the ERM concept. (Gordon, Leob \& Tseng 2009, p.301) 


\section{In 2004, COSO defined Enterprise Risk Management (ERM) as:}

a process, effected by an entity's board of directors, management and other personnel, applied in strategy setting and across the enterprise, designed to identify potential events that may affect the entity, and manage risk to be within its risk appetite, to provide reasonable assurance regarding the achievement of entity objectives. (as cited in Kirkpatrick 2009, p.7)

Because risks are by their nature dynamic, fluid and interconnected, the best way to manage them is through an integrated approach. Such a portfolio view of risks will lead to organisational effectiveness, better risk reporting and enhanced business performance amongst others (Lam, 2003). Although people tend to focus on the negative connotations associated with risk, there are indeed several upsides and possibilities for gain. In the business context, for example, risk will always be connected to new opportunity; therefore, companies must be willing to take on at least some degree of risk in order to succeed (Panaggio 2013). Knowing when and how much risk to assume is essential for firms because of the potential for severe crisis when risk manifests. The willingness of an investor to bear a risk is known as risk appetite and depends on two different factors: the extent of the investor's dislike for that uncertainty and the extent of that uncertainty (Gai and Vause 2005).

As was previously noted, the field of risk management has undergone dramatic changes in recent decades. For a majority of the 1980s and 1990s, most large companies employed a risk manager who was responsible for overseeing the company's insurance transactions. Now, in today's business environment, the scope and objective of corporate risk management has grown to include all different types of corporate operations and strategic risks. Now, instead of having a corporate risk manager, firms often choose a chief risk officer who holds a position in senior management. Essentially, risk management has expanded from simply alleviating deviations from the earnings trajectory, to protecting the entire firm's sources of future earning power (Chew 2008). Bob Anderson, who is the executive director of the Committee of Chief Risk Officers, summarizes the changing dynamics of the sector: "Corporate risk management is no longer a just a series of isolated transactions...risk management is clearly a senior management function that requires input and collaboration from all levels of company operations" (Morgan Stanley Publication 2005). These views reiterate the increasing awareness of the importance of risk and how to handle it.

\subsubsection{Critical Review of the Stakeholder Management Approach}

Although research on stakeholders reveals many elements separately, it is surprising to mention the minimal efforts that have been put to establish comprehensive models for managing stakeholders. Aggeri and Acquier (2005) recommend a model for involving stakeholders with an interpretive vision (understanding the practices of companies) and an instrumental one (managing relations with stakeholders). This approach made up of the four key elements : 1) any company have stakeholders who raise requirements 2) not all stakeholders can influence the company in the same way; 3 ) the well of of the corporation depends on its potentils to meet the requests of key stakeholders; 4) thkey role of top management is to arbitrate between the potentially contradictory demands of the stakeholders. is restrictive insofar as it only takes into consideration the scenario of the stakeholders supporting various interests. Aggeri and Acquier's model (2005) became more improved later on stating: 1) all corpoations have stakeholders with requirements with regard to them, but also in regard of whom the corporation perhaps have demands; 2) few stakeholders can influence the organisation, as well as, the organisation can not influence all its stakeholders; 3 ) achieving the corporate objective relies on the organisation's ability to act on its key stakeholders; 4) therole of management is to arbitrate between its organisational needs and the potential contradictory requests of stakeholders.. Preble (2005) adds to this debate developing a model for managing stakeholders that is designed to be comprehensive. His model has the merit of integrating a number of analysis for the stakeholder theor.. This theory is particularly relevant in explaining the actor's behaviour in a changing process. It insists on the process by which the organisational change is conducted

Much like risk management, the term stakeholder management is relatively new despite the fact that its basic concepts have been around for several decades. A stakeholder is any individual, group, or organization that can affect or be affected by a firm's activities. These can include customers, suppliers, property owners, etc. Although traditional shareholder value maximization should theoretically lead to the highest firm earnings, the stakeholder approach aims to solve three key problems (Freeman et al. 2010).

First is the problem of value creation and trade. In the present times, business relationships can change depending on the national, industrial, and societal context. Essentially, there are changing external factors that affect the economics of business and must also be considered. Next, we have the problem of ethics in capitalism. Although this economic system has led to substantial technological advancements and human progress, it has also created societal inequality that places those whore are unable to compete with new technologies at a 
significant disadvantage (Frieden and Rogowski 2013) while attempts to solve the problem of value creation and trade under a strict shareholder value approach only serve to intensify the problem of ethics in capitalism.

The third problem that the stakeholder approach attempts to overcome is the economically centered managerial mindset. It is suggested that often, this type of business mentality is simply not suitable for the turbulent nature of the modern business environment. The challenge is to redefine economic theory so that it incorporates modern day ethical challenges with business matters and managers can combine elements from both in their decision making process. Furthermore, it is suggested that business schools might need to change what they teach in order for future leaders to be properly prepared to deal with modern challenges (Freeman et al. 2010). Stakeholder theory implies that if the relationship between a company and all of its stakeholders is used as a measure of analysis, the three problems stated earlier may be overcome.

Freeman (1994) points out that most traditional business theories stress the separation of business decisions from ethical ones hence the common joke "business ethics as an oxymoron". It seems, however, that this way of thinking has just perpetuated many of the problems that exist in our society today. Attempts to solve these problems with the traditional shareholder value mentality displays an element of reflexivity as the cause and effect actually affect one another: Increased attempts to solve problems lead to more problems which lead to more attempts and the cycle continues indefinitely.

Business as usual, government as usual, and even protest as usual are not promoting the progress that we need as a society therefore, large scale collaboration will be necessary to bring about positive change (Hohnen 2001). Many modern day issues are incapable of being resolved with any single set of decision makers from the government or any other sector. Rather, these issues require cooperation between different stakeholders in working out the solutions, their implementation, and the monitoring of results (Hemmati 2002).The stakeholder management approach includes various analytical procedures for planning and developing corporate strategy with stakeholders and is based on the idea that strong ethical principles can result in tremendous competitive advantage (Weiss 2008). In the real world, there are three dimensions to stakeholder management: identifying stakeholders, maintaining a solid relationship with them, and improving existing relationships (Smudde and Courtright 2011). Companies cover these three elements by forming processes that strive to gather all major stakeholders in a new circle of communication and decision making on various issues. These processes must be based on an awareness of the importance of maintaining equity and accountability, as well as an awareness of the democratic principles of transparency and participation between the stakeholders.

Despite the many positive aspects of the stakeholder approach, there are several barriers that impede the implementation of this strategy. For starters, non- governmental organizations lack funding and often times governments are incapable or reluctant to develop a consistent approach to stakeholder involvement. More importantly, however, there is a general unwillingness to engage on the part of many individuals and organizations for various reasons. Minu Hemmati (2002) stresses that businesses tend to have a stubbornness that prevents them from understanding that stakeholders, rather than just shareholders, should have a say in their policies. Under this mindset, companies believe that no groups or individuals should have any say in operations as long as they are within government regulations.

Deborah Tannen (1998) believes that there is a strong element of "the argument culture" in society today. This refers to the widespread automatic tendency to aggressive forms of communication, confrontational exchange, military metaphors, and thinking in dualisms. There are two sides to every coin therefore Tannen (1998) suggests a shift from debate to dialogue rather than fighting and heated discussion. This also means that people need to start listening rather than just hearing because dialogue is the foundation for integrating diverse views in order to form solutions for complex problems. Now that we have covered some of the relevant theoretical elements, we may begin to make the argument that the stakeholder management approach is a multifaceted strategy that serves as an effective risk management policy and simultaneously fulfills the objectives of various other management policies as well. We are able to support this argument through analysis of real world scenarios. Davies (2013) presents a large scale sporting event such as the Cricket World Cup which we will use as a preliminary example. An even such as this is accompanied by tremendous media attention which provides millions of people around the world a chance to watch the sports competition, which in reality is just a component of the entire event. For an event like this to be successful, effective risk management is an essential, yet challenging, component. We begin to see the reflexivity element again because as a stakeholder's interests increase, so does media attention which leads to more risk.

As a result of the increase in risk, more stakeholders become involved once again. Because of this reflexive relationship, an event as huge as a World Cup carries high levels of risk and many stakeholders who all 
want a successful event. The problem now becomes that the criteria for success to different stakeholders changes because they have different perspectives. The host nation is concerned with conducting a successful event in their country whereas the governing body, International Cricket Council (ICC), is concerned with the successful completion of the event regardless of where it is held. Although the difference seems very small, if a dangerous accident were to potentially threaten the staging of the event, the host nation would focus on a short-term postponement.The governing body, on the other hand, might prioritize possibly obtaining a new host nation and relocating the event in order to stay on schedule. Law enforcement agencies, event organizers, and private security are also all involved in a mega event. Sound communication is necessary to ensure an effective division of labor so that the different groups do not become counterproductive to one another. Similarly, event organizers and sponsors must collaborate because the sponsor expects positive brand exposure as compensation for providing funding to hold the event in the first place. In the case of inclement weather, the event organizer must consider the contracted sponsor rights while also attending to other areas of risk such as spectator and player safety. The World Cup example shows us that the consolidation of many different objectives into one big picture approach is essential for a mega event to succeed. When the stakeholders work together, potential risks are more easily identified and interdependencies between groups can be highlighted (Davies 2013). This approach proved to be effective because the event was staged successfully. Spectators were entertained and players, sponsors, vendors, and media agencies all profited financially without dispute. The ICC, host nation, governments of participating nations, and law enforcement agencies all followed the same framework, which allowed the whole tournament view on risk to be developed and successful executed. In this event, as well as many others that follow the same approach, the act of engaging in stakeholder management highlights potential risks seemingly on there own. This case supports our argument that the stakeholder approach is also an effective risk management policy as it relates to large scale sporting events but the same principles also can also be applied successfully in the business environment and the remainder of cases in this report,, will focus on businesses, rather than sporting events.

\subsection{Application in Practice}

\subsubsection{1st Case Study}

A large private retailer is Wal-Mart based in the United States (Fortune 500) and offers a wide spectrum of goods such as clothes, pharmaceuticals, food, electronics, automotive accessories, sporting items, and much more. Sam Walton founded the company in 1962 and from the beginning; his philosophy has been to promote a higher volume of sales by accepting lower profit margins and portraying his low prices as a major attraction to consumers (Tedlow 2001). The concept was very profitable and within the first five years of being open, had expanded to 24 stores and generated over $\$ 12$ million of sales (PBS Frontline). Now, Wal-Mart has over 11,000 stores worldwide and stand out from other retailers because of the extent to which they have used economic globalization to prioritize the interests of customers and shareholders above other parties like employees, unions, competitors, and suppliers (Boutilier 2011).

Resultantly, there are many that have benefited from their operation and many that have suffered. WalMart is a massive institution not only in regards to their store sizes but also economically. For the purposes of comparison, we observe that in 2013, competitors such as Sears and Macy's accumulated revenues of $\$ 36$ billion and $\$ 27$ billion respectively while Wal-mart, on the other hand, managed to generate over $\$ 476$ billion in the same year. To put this in perspective, the GDP of Nigeria as a nation in the same year was $\$ 479$ million (Fortune 500). Due to the shear size of Wal-Mart, it is easy to understand that many, many issues have been raised against the company that span a wide variety of topics.As we can from the numbers, Wal-Mart is flourishing economically and dominating their so-called "competition" but this comes with other important implications. We will now look into some of the issues/protests that have been raised against this mega retailer and take a look at how their corporate strategy has affected various stakeholders either positively or negatively. Based on the companies various upsides and shortcomings, we will asses the effectiveness of their strategy which we will integrate with our argument for the stakeholder management approach.Wal-Mart is notorious for offering and aggressively advertising very low prices; this is one of the main reasons that so many consumers are attracted to their stores. The reality of the situation is that the low prices come at the expense of many other people/groups: Even the customers, who are thrilled with low prices, see negative effects from the lower quality associated with the cheaper goods. This is one of the most common complaints against the company and the first issue that we will asses. "Wal-Mart Watch" is a public education campaign dedicated to challenging the world's biggest retailer to improve a wide spectrum of shortcomings. David Nassar (2007), executive director of the campaign, points out that dangerously cheap products have lead to E. coli tainted meat, melamine in dog food, and even lead paint on children's toys; all of which underwent product recalls. Nassar (2007) states that in order to 
cut costs, Wal- Mart has moved production to countries with weaker labor and environmental standards.

Their continual desire for lower prices means that manufacturers are pressured to abandon sensible methods and instead begin to cut corners on materials, labor conditions, and ultimately quality. If suppliers are unable or unwilling to reduce prices by at least 5 percent annually, Wal-Mart will either stop selling a particular item completely or they will simply find a different supplier that can meet their desired price (Ferrell, Fraedrich and Ferrell 2010). Due to the nature of the company's risk appetite, they continually pressure manufacturers to lower costs, which essentially transfer much of the price risk, back up the supply chain to the manufacturer (Zsidisin and Hartley 2012). In this aspect, we can see that lack of attention to customer health is yielding negative results. In some instances, Wal-Mart even continued to sell products that had undergone recall. This really shoes that the company has such a deeply ingrained shareholder value approach that they prioritize profit maximization over consumer safety. If a true stakeholder approach had been employed, it is likely that dangerous products that were recalled might not have been on the shelves in the first place because the marginally cheaper products would not meet acceptable standards as they can have detrimental effects on consumer health. For this scenario, we will argue that the company's refusal to consider the customer's health over their profits lead them to assume the increased risk of harming some customers.

This risk manifested on several occasions leading to crisis and product recalls. We will use the product recalls and sick or injured customers as criteria to deem Wal- Mart's risk management strategy as ineffective in regards to product quality. This fully supports our argument for the stakeholder approach, as the company could have avoided risk and crisis by employing it. Another big issue that has been raised against Wal-Mart is that they have very poor employee relations. Over the past twenty years, the Equal Employment Opportunity Commission (EEOC) has filed fifteen lawsuits against the mega retailer; only 5 of them have been resolved and the other ten are still pending (Ferrell, Fraedrich and Ferrell 2010). The basis of these complaints ranges from alleged discrimination on the basis of age, sexual orientation, and most commonly gender. Women comprise 67 percent of the Wal-Mart workforce but only about 33 percent of their managers are women according to ABC News (2014). This discrepancy was used as support for the 2007 Dukes v. Wal-Mart Stores lawsuit alleging that women faced discrimination against receiving promotions. A class action suit covering all former and current female employees was sought but eventually could not proceed in court although several women proceeded individually (New York Times 2011).

According to Joe Sellers, lawyer for one of the plaintiffs, "Wal-Mart has operated the largest glass ceiling for its women employees and we want to shatter it." He also continued to add that they hoped to break down the company procedures that prevented women from being treated fairly. Similar qualms have been raised about age and disability discrimination. This will have negative implications on the corporate reputation, an issue that will be covered in further detail. Additional employment issues are complaints about low wages, poor working conditions, insufficient health care, and opposition to the company's stringent policies against labor unions. In 2001, sales clerks averaged an hourly rate of $\$ 8.23$, which equates to an annual salary of $\$ 13,86$, a value that failed to meet the federal poverty line for a family of three at the time (Bianco and Zellner 2015). When one adds the fact that 46 percent of these employees are uninsured (Ferrell, Fraedrich and Ferrell 2010), the sentiment of displeasure from the workers seems justified. From the information we have gathered about Wal- Mart's employee relations, we can observe elements of the scientific management theory in their approach. This theory starts with the assumptions that employees are prone to avoid work whenever possible, have limited, selfish aspirations, and are immature in the ways of work (Abbott 2006). In attempt to mitigate risk from these behavioral employee assumptions, companies that chose to follow this form of management practice should treat employees impersonally and collectively while reducing work to its basic elements; effectively reducing required skill to a minimum.

This management approach seeks to suppress internal tension over the distribution of organizational power by ensuring that management retains superior knowledge about the structure of work, and has the authority to direct workers as it sees fit (Abbott 2006). Wal-Mart appears to follow the prescriptions of this theory very closely, although implications are that employee satisfaction is quite low and internal tensions are merely suppressed rather than resolved. When you combine that with a well documented record of recalls for low quality products, corporate reputation suffers as well. We will use the numerous lawsuits against Wal-Mart as additional criteria for failure as it relates to their risk management approach. Had this mega retailer employed better stakeholder management, they could have avoided at least some of the lawsuits and the costly compensation settlements.Due to the vastness of the corporation, the effects of their actions surpass just their own company because the entire retail industry must engage in similar practices in order to stay in business. As the biggest and most influential retailer in the United States, it is unfortunate that Wal-Mart fails to 
implement sufficient stakeholder management. Their financial success is unquestionable, however the aggressive shareholder mentality coupled with certain stakeholder neglect leaves doubt that the financial profits are worth ethical and other implications that cannot be measured financially such as reputation. For our scope of study, the Wal-Mart case supports our arguments for the stakeholder approach.

\subsubsection{Corporate Reputation Management \& Corporate Social Responsibility}

Corporate reputation is a function of the views and attitudes of various stakeholder groups and individuals and rests on assessments made by individuals outside the organization (Highhouse et al. 2009). Trust and confidence are two of the most important elements that affect corporate reputation and according to Earle (2009) they represent two uniquely distinct elements. Trust is relational and is based on shared values such as integrity, benevolence, morality, fairness, and caring. Confidence, on the other hand, is based on past performance and experience with a company. This implies that a good reputation requires that the corporation be based around strong values, typically outlined in a mission statement, and that they consistently perform in line with these values. The key here is that both elements are a requirement; if one is missing, the reputation is tarnished. Without trust, a company will never have the opportunity to perform. Similarly, a company will quickly suffer loss of reputation if they continue to perform poorly regardless of how appealing their mission statement may be. Because corporate reputation cannot easily be measured quantitatively, many question if it matters at all. Multiple studies/surveys have shown that the most "admired" Fortune 500 companies have a price to earnings ratio that is approximately 12 percent higher than less "admired" companies (Dube 2009) which accounts for a staggering $\$ 5$ billion increase in market capitalization. This implies that there is a strong correlation between reputation and profit gain. An increasing number of firms are making this realization, as evidenced by results from a Conference Board survey of 148 business executives that show 81 percent of major companies have made substantial efforts to improve their reputation risk management in the past 3 years. Although the different stakeholders may have different perceptions of a company's reputation, those of the customer and employee are especially key (Burke, Martin, and Cooper 2011). This is one of the important concepts that Wal-Mart failed to realize in our earlier case as they had major shortcomings in this regard.

Building a positive corporate reputation requires the following steps: formulating a corporate strategy and important elements for sustainability, integrating social responsibilities into the corporate strategy, developing a reputation risk management strategy, communicating with internal and external stakeholders, and building a strong corporate culture that attracts and retains talent (Burke, Martin, and Cooper 2011). It quickly becomes apparent that if a company follows the stakeholder approach, they already fulfill a majority of the elements of reputation management.

From studying the Wal-Mart case, we have learned that an aggressive shareholder value strategy can lead to tremendous profits when properly executed however there is a missing component. Wal-Mart has become the largest and most profitable retailer in the world, yet they fall short in several other aspects. Corporate social responsibility is the commitment to improve community well being through discretionary business practices and contribution of corporate resources (Kotler and Lee 2005). An important element of this definition is that it refers to discretionary practices; these do not include legally mandated activities or those that are societally expected. Rather, these are voluntary initiatives from the company to improve human conditions and/or to address environmental issues. Firms often have a mindset that they do not need to engage in such activities because they do not lead directly to company profits.

From their research and experiences, they have concluded that when companies fulfill their CSR, they indirectly experience bottom line benefits like increased market share, stronger brand positioning, enhanced corporate image, increased ability to retain quality employees, lower operating costs, and higher appeal to investors.Similarly to reputation management theory, most of the elements for fulfilling CSR are effectively covered by firms that chose to employ the stakeholder approach. This supports our argument that the stakeholder approach is a diverse and multifaceted business method that simultaneously meets the objectives of risk, crisis, and reputation management while fulfilling corporate social responsibility and still increasing shareholder value. In contrast to our previous case analysis of Wal-Mart, our next case will demonstrate the positive implications from a successful application of the stakeholder approach.

\subsection{2 $2^{\text {nd }}$ Case Study}

Our previous cased proved that regardless of extreme financial success, a company's failure to engage or value important stakeholders can have serious repercussions in regards to crisis, risk, and reputation. Thus far, we have argued that the stakeholder approach can mitigate risk and help prevent the occurrence of crisis. We will now 
make the argument that companies who use a stakeholder approach can reap positive benefits when crisis does occur. A crisis, which usually carries the element of surprise, is an unpredictable event that has the capability of harming an organization and/or it's stakeholders (Goel 2009). As we have already covered, there are ways to prevent crisis or reduce the risk of its occurrence however, accidents can and do happen in the real world and even the most cautious firms are vulnerable.

Most current literature about crisis management stresses the significance of effective leadership following the onset of the crisis (Ulmer 2001), however this case will show the benefits of good stakeholder management practices both before and after crisis and how they can aid a company that is struggling. The first benefit is that stakeholders have a true interest in the success of the organization and may serve as a support network in times of crisis by providing their crisis mitigating resources (Ulmer and Sellnow 1995). Firms that possess weak stakeholder relations tend to find that the various groups that are also affected by the crisis will not simply withdraw support, but can also add fuel to the fire, which serves to prolong or intensify the crisis. We saw this in the Wal-Mart case when, in the midst of product recalls for low quality goods, several lawsuits were dropped on the company. Once an organization has determined value positions on important issues, they should work to promote open communication with stakeholders so that they may develop alliances, good will, and mutual understanding (Ulmer 2001).

Malden Mills was a textile manufacturing plant in Lawrence, Massachusetts famous for inventing a fabric known as Polartec (Leung 2003). In December 1995, the plant burst into flames and although there were no fatalities, 36 workers were injured. The fire, which was deemed to be an industrial accident, destroyed three important manufacturing buildings and threatened the jobs of approximately 3000 employees in a small manufacturing town. Aaron Feuerstein, owner and CEO of Malden Mills, was able to resolve the crisis and received widespread praise for the care and responsibility he showed his community following the fire. For purposes of our study however, we will focus on how Feuerstein's stakeholder practices before, during, and after the fire ended up helping his company through the crisis.

Effective crisis management is more than just damage control and usually requires solid risk management elements if it is to succeed. This means planning and preparing for its potential onset far in advance. One of the most crucial features of this is managing the firm's complex web of stakeholder relationships (Ulmer 2001). In December of 1997, two years after the fire, Aaron Feuerstein and several key stakeholders for Malden Mills were interviewed in an effort to shed light on two different aspects of the case. The first agenda focused on understanding Feuerstein's values, main concerns, and decision-making processes while the second was to get a better understanding of the nature of Malden Mills' internal and external stakeholder relationships (Ulmer 2001). The information from these interviews will be used extensively for the remainder of our case analysis.Jeff Bowman, head of crisis coordination and corporate communication for Malden Mills, identified the company's stakeholders as the "employees and their families, the community, customers, vendors, the government, and the press".

\subsubsection{Crictical Review of the Case Studies}

Freeman (2010) points out that companies wishing to adopt stakeholder management should usually asses the stakeholder's needs so that they have a solid understanding of the most affected groups and least affected groups. With this understanding, the company leaders can more effectively prioritize efforts to develop relationships with primary stakeholders before secondary stakeholders. For Malden Mills, the community and the employees represented primary stakeholders while secondary stakeholders included customers and the media. Malden Mills was able to build a strong, positive relationship with its workers. Feuerstein dedicated extensive time to working with the labor union to ensure that his own employees were being treated fairly. Despite the fact that Malden Mills had been a union factory for many decades, they never had a strike; one of the biggest sources of pride for Feuerstein (Hartman and DesJardins 2008). Paul Coorey, leader of the nearby union for textile workers, stated that Feuerstein's employee methodology was a belief that if the workers were paid well and given adequate benefits to support their families, they would perform well. This belief was supported by the fact that Malden Mills was the highest paid textile factory in the United States (Melewar 2008). This whole mentality towards employee relations is a polar opposite to that of Wal-Mart for several reasons. Wal-Mart strongly discourages union activity while Malden Mills uses unions as a resource to improve the relationship with employees. Wal-Mart pays employees minimum wage, while Malden Mills compensates their employees with industry leading salaries. Wal-Mart discriminates against certain employees, while Malden Mills was "always fair and compassionate".

In our previous case analysis, we determined that Wal-Mart followed principles of the scientific management 
theory for the workplace. In Malden Mills, however, we can see some elements of the human relations theory and even more from the human resource management theory. Under the human relations theory, companies must grant employees the right to influence the manner in which they are governed. This is because this theory seeks to reduce internal tensions by promoting the sense of workplace satisfaction (Abbott 2006). Feuerstein definitely grants his employees the right to have a say in their governance as evidenced by his cooperation with the labor unions. He also promotes workplace satisfaction but not with the same aims as the human relations theory. The human resource management theory, on the other hand, is based on the belief that managers and employees are more alike than they are different. Companies subscribing to this theory should promote communication and collaboration between managers and employees while developing a unified culture, strong leadership, and a clear vision of company objectives. The aim of this theory is to resolve internal tensions by eliminating workplace social classes, developing communication and engagement with the stakeholders, and avoiding conflict by promoting teamwork (Stone 2002). This is exactly how Feuerstein structured his workplace and as we have seen, this approach for employee relations produces workers that want to work hard for the company rather than filing lawsuits against them like in the case of Wal-Mart. Malden Mills identified their community (Lawrence, MA) as another primary stakeholder perhaps because the Feuerstein family founded and has been operating the company in the Merrimack Valley region of Massachusetts for over a century (Nelson and Kanso 2008). Lawrence along with surrounding cities is highly reliant on the textile industry. Often times, entire households worked for Malden Mills, which would explain why a majority of the economy depends on their operations (Ulmer 2001).

Many years ago, Massachusetts had a high density of mills but by the early 1990s, Malden Mills was one of the few remaining in the region because many others moved south or offshore in order to escape union activity and cut production costs. Regardless, Aaron Feuerstein insisted that his company would stay put because the employees' technical skills outweighed the benefits of cheaper production costs. This really displayed the level of commitment and loyalty that he had for his workers and his community.Additionally, Feuerstein proved his dedication to his community on numerous different occasions. For example, there are several instances where he decided to extend generous credit lines that essentially saved other local businesses. Aaron Feuerstein and his brother even came forward to donate $\$ 2$ million to rebuild a local synagogue when it burned down in 1994 (Ulmer 2001). These actions really reiterate the tradeoff between Feuerstein and his community because most of his employees are from the area. By supporting the community through all of these generous and significant contributions, Feuerstein was able to build a strong positive reputation largely through loyalty and trust. Aaron Feuerstein had a solid understanding of the concept that no stakeholders should be neglected. For this reason, he dedicated significant effort to maintain positive relationships even with the company's secondary stakeholders: customers and media. Malden Mills had many high profile corporate customers such as L.L. Bean, The North Face, Patagonia, Ralph Lauren, and even all branches of the United States military and what many people fail to realize is that Malden Mills produces over $70 \%$ of some their corporate customer's product lines (Ulmer 2001). Implications are that the company is mutually dependent with its corporate customers and communication is necessary so that they can be informed about production delays or other relevant information.

An example of this occurred very early in 1995 when the Consumer Product Safety Commission (CPSC) announced on live news that fleece jackets were highly flammable (Business Wire 1995). Since fleece is one of Malden Mills' main products, the company had to respond quickly to guarantee customers that the CPSC announcement did not refer to their products and that they were safe. This event enlightened the company as to the power of media to spread important information very quickly.Because the media can spread information to the public on such a large- scale, they assume the role of a key stakeholder to a majority of companies, especially the larger firms. As such, the organization should strive to promote open communication with them in a similar manner to their other stakeholders. According to Jeff Bowman, Malden Mills made a deliberate effort to be "open, candid, and accessible" to the media. For example, the company used the media to present the facts of the situation to the public and clear and customer doubts that their products were safe. As one can gather just from the names, the two secondary stakeholder relationships, with customers and the media, received less attention than the employees and community because of less daily interaction. Nevertheless, Feuerstein made certain that he established and maintained cordial and open communication with all of his stakeholders.

\subsubsection{Stakeholder Management During and After a Crisis}

We have now assessed the means with which Aaron Feuerstein and Malden Mills used the stakeholder approach to effectively benefit the company pre crisis. We will now analyze how continued management of the 
stakeholders during and after the onset of crisis can also greatly behoove a firm by reducing the effects of the crisis. When the factory burned down, employees were unsure about their futures, the community as a whole was at risk of losing their biggest employer, and it appeared as if Feuerstein had the potential to suffer extensive financial loss. The company faced a difficult challenge to recoup from crisis over the next several months. Similarly to many related accidents, there were very high levels of uncertainty with the company as well as its stakeholders. Shortly after the occurrence of this type of crisis, people are mostly concerned with discovering the cause of the accident along with how to prevent them in the future. The media typically adds to the franticness of the situation with extensive news reports and updates from the scene of crisis. Aaron Feuerstein acted quickly to remove uncertainty and apprehension before they had time to develop further amongst the various stakeholders. To the delight of many and wile the factory was still burning in the background, he proclaimed that, "We're going to continue to operate in Lawrence" and added that they "had the opportunity to run south many years ago. We didn't do it then and we're not going to do it now." To add to the worker's delight and to the shock of many business analysts amongst others, Feuerstein added that all of the employees would continue to receive their salaries for the following 30 days (Gasparski, Ryan and Kwiatkowski 2010). One month later, he announced that the pay would continue for an additional 30 day period because he considers the employees to be the company's most valuable asset unlike other leaders who view them as an being expendable. This appears to be aimed at CEOs who tend to downsize their workforce in attempt to generate short-term profits. Ultimately, the extensive efforts of Feuerstein along with tremendous contributions from the community kept Malden Mills running for the following 6 years until they were forced to declare bankruptcy in 2001 due to the high payroll and rebuilding costs after the fire. Although Aaron Feuerstein lost control of his company, Malden Mills was able to achieve solvency due to the generosity of various creditors and subsidies. This case reiterated that the quality of the stakeholder relationships with the company is overwhelmingly based on mutual interdependence (Nelson and Kanso 2008). Corporate reputation is built from an aggregate of actions over time and Malden Mills certainly built themselves a strong one centered on elements such as trust and loyalty. It has been twenty years since the factory fire, yet Malden Mills and Aaron Feuerstein are still a model case for how effective stakeholder management should be conducted. Critics will reject this case as being a failure since Feuerstein ultimately lost control of his family business. We disagree because it is important to remember that investigation deemed the fire to be caused by an industrial accident, whatever that may mean. Considering that the cause of this crisis is still relatively ambiguous, it is impossible to blame the company because had they not been so unlucky as to have the fire, Aaron Feuerstein could potentially still be running a very successful company. This realization makes his tendency to put responsibility to others over his own interest even more commendable.

\section{Conclusion}

This study argued that the stakeholder management approach to business is an effective strategy because it serves a wide spectrum of functions such as risk and reputation management. Furthermore, the stakeholder mentality promotes fulfillment of a company's corporate social responsibility because of the mutual interdependence that both sides must understand and protect. After some theory analysis and propositions, we tested our argument by applying it to two case studies. The Wal-Mart case proved that shareholder value is not the only factor in business. By neglecting relationships with key stakeholders, such as the employees, crisis can occur in the form of lawsuits and corporate reputation may be tarnished. It is important to note that the negative implications here may take quite long to onset. The Malden Mills case reiterated that strong ethics along with carefully nurtured stakeholder relationships could create advantage for a firm. Their reaction to the CPSC reports show that the stakeholder approach can effectively mitigate many risks but the fire teaches us that some are simply unavoidable. In the face of corporate disaster, the stakeholder approach strengthens support systems when they are most needed. Essentially, we can think of effective corporate strategy in this manner: employing effective stakeholder management means that a company must fulfill their corporate social responsibility; when a company has fulfilled their corporate social responsibility, the corporate reputation is positive; and when the corporate reputation is positive, competitive advantage is gained.

\section{Acknowledgments}

Acknowledgement is attributed to the research work of the first author for the completion of the manuscript following directions and feedback of the corresponding author for its improvement \& completion.

\section{References}

Abbott, K. (2006). A Review of Employment Relations Theories and their Application. Problems and Perspectives in Management, 1, 1-10. 
Bianco, A., \& Zellner, W. (2015). IS WAL-MART TOO POWERFUL? Low prices are great. But Wal-Mart's dominance creates problems -- for suppliers, workers, communities, and even American culture. Business Week, (3852).

Burke, R., Martin, G., \& Cooper, C. (2011). Corporate reputation. Farnham, Surrey: Gower.

Chew, D. (2008). Corporate risk management. New York: Columbia University Press. https://doi.org/10.7312/chew14362

Davies, D. (2006). Reputation Risk Management-A Holistic Approach. Retrieved from http://www.idrisk.com/v2articles/189_Reputation_Risk_-_Holistic_Approach.pdf Last visited on 4th May, 2013

Davies, J. (2013). A Multi Stakeholder Approach to Risk Management at Mega Events. Risk Dialogue Magazine, $1-4$.

Dionne, G. (n.d.). Risk Management: History, Definition and Critique. SSRN Journal.

Dube, I. (2009). Corporate governance. LexisNexis.

Ferrell, O., Fraedrich, J., \& Ferrell, L. (2010). Business ethics. Mason, OH: South-Western Cengage Learning.

Feuerstein, A. (2003). The Mensch of Malden Mills.

Freeman, R. (2010). Strategic management. Cambridge [u.a.]: Cambridge Univ. Press. https://doi.org/10.1017/CBO9781139192675

Freeman, R., Harrison, J., Wicks, A., Parmar, B., \& de Colle, S. (2010). Stakeholder Theory: The State of the Art. Cambridge University Press, pp.4-8. https://doi.org/10.1017/CBO9780511815768

Gai, P., \& Vause, N. (n.d.). Measuring Investors' Risk Appetite. SSRN Journal.

Gasparski, W., Ryan, L., \& Kwiatkowski, S. (2010). Entrepreneurship. New Brunswick: Transaction Publishers.

Goel, S. (2009). Crisis management. New Delhi: Global India Publications.

Hartman, L., \& DesJardins, J. (2008). Business ethics. Boston: McGraw- Hill/Irwin.

Hillson, D. A. (2003). Effective Opportunity Management for Projects: Exploiting Positive Risk. New York, US: Marcel Dekker. https://doi.org/10.1201/9780203913246

Holmes, A. (2004). Smart Risk. Capstone Publishing Limited (A Wiley Company): The Atrium Southern Gate Chichester

Larkin, J. (2003). Strategic Reputation Risk Management. Houndmills Basingstoke, Hampshire RG2 6XS. pp. 36. https://doi.org/10.1057/9780230511415

Peterson, G. E. (2006). Interactive Risk Management Systems and Method with Reputation Risk Management. United States Patent Application Pub, No. US 2006/0116898 A1

\section{Copyrights}

Copyright for this article is retained by the author(s), with first publication rights granted to the journal.

This is an open-access article distributed under the terms and conditions of the Creative Commons Attribution license (http://creativecommons.org/licenses/by/4.0/). 